\title{
Wartości i postawy w emocjonalnych narracjach medialnych. Analiza zawartości przekazów mediów mainstreamowych w okresie pierwszej fali SARS-CoV-2
}

\section{Wprowadzenie}

Dodstawowym elementem każdej kultury są wartości kulturowe definiowane jako „wartości społecznie usankcjonowane, typowe dla danej kultury, uwewnętrznione przez członków społeczeństwa, które pomagają im dokonywać wyborów, ukierunkowują i wskazują cel oraz środki działania, a także wzmacniają samo działanie w ramach tej dziedziny społeczno-kulturowej, w której same tkwią"1. Obok wytworów kulturowych i postaw, zwracających się ku wartościom ${ }^{2}$ i będących względnie trwałą dyspozycją do oceniania przedmiotu i emocjonalnego nań reagowania ${ }^{3}$, lub też będących pewną trwałą tendencją do wykonywania pewnego rodzaju działań i doświadczania określonego rodzaju uczuć w konkretnych rodzajach sytuacji ${ }^{4}$, stanowią one centrum kultury, które jest niezwykle ważnym elementem społecznego trwania. To ono określa, w jakim kierunku społeczeństwo będzie się rozwijało, jakie elementy zaczerpnie z innych kultur, jak oceniane będzie postępowanie członków tego społeczeństwa. Wartości

* Dr Joanna Szegda - Katolicki Uniwersytet Lubelski Jana Pawła II, e-mail: joanna.szegda@kul. pl, ORCID: 0000-0002-1129-0125.

1 L. Dyczewski, Kultura polska w procesie przemian, TNKUL, Lublin 1995, s. 58.

2 A. Kłoskowska, Kultura, w: Encyklopedia kultury polskiej XX wieku. Pojęcia i problemy wiedzy o kulturze, red. A. Kłoskowska, Wiedza o Kulturze, Wrocław 1991.

3 S. Nowak, Pojęcie postawy w teoriach i stosowanych badaniach społecznych, w: Teorie postaw, red. S. Nowak, PWN, Warszawa 1973, s. 23.

${ }_{4}$ C. Geertz, Interpretacja kultur. Wybrane eseje, tłum. M. Piechaczek, Wydawnictwo UJ, Kraków 2005, s. 118. 
i postawy należące do centrum kultury są także czynnikami ułatwiającymi bądź utrudniającymi postęp cywilizacyjny ${ }^{5}$. Samo centrum kultury zdefiniować można jako „zintegrowany zbiór swoistych i ważnych wartości (zwanych centralnymi lub rdzennymi) powszechnie uznawanych, utrwalających je wytworów i ukształtowanych w związku z nimi wzorów reakcji uczuciowych, struktur myślowych, wzorów międzyosobowych, kontaktów wewnątrz społeczeństwa, jak też tego społeczeństwa z innymi społeczeństwami”'. Cechą charakterystyczną każdego centrum kulturowego jest zmienna ważność tworzących go wartości. Poszczególne wartości stają się dominujące w określonych warunkach, podczas gdy inne w tym samym czasie są mniej akcentowane. Olbrzymią rolę w definiowaniu ważności wartości i postaw, jako że kultura jest ich społecznym wyborem ${ }^{7}$, pełnią media.

Współczesna kultura jest kulturą emocjonalnych przepływów, nieustannej dyfuzji emocji ze sfery prywatnej, intymnej, do wspólnej, publicznej ${ }^{8}$. Media, a zwłaszcza Internet, stały się idealnym narzędziem publicznej artykulacji intymnych odczuć, przemyśleń i emocji także przez media masowe, zwłaszcza na ich oficjalnych profilach w mediach społecznościowych. Technologiczny reżim emocjonalny to przede wszystkim dyktat intensywności emocjonalnej, w którym liczy się ilość emocji ${ }^{9}$. W social mediach granica między tym, co publiczne i prywatne, indywidualne i kolektywne, zaciera się. Co więcej, komunikacja cyfrowa, w jej czasowej dynamice i intensywności, może być szczególnie rozumiana w odniesieniu do „przepływów afektywnych"10. Media społecznościowe to media emocji ${ }^{11}$. Takie cechy nowych mediów jak interaktywność, otwartość czy intertekstualnośćc ${ }^{12}$ dały odbiorcom możliwość aktywnej kontroli przekazu,

${ }^{5}$ L. Harrison, Wstęp. Dlaczego kultury nie sposób przecenić?, w: Kultura ma znaczenie. Jak wartości wpływaja na rozwój społeczeństw, red. L.E. Harrison, S.P. Huntington, tłum. S. Dymczyk, Zysk i S-ka, Poznań 2003, s. 23.

${ }^{6}$ L. Dyczewski, Trwałość i zmienność kultury polskiej, Akademia Społeczna, Wojewódzki Dom Kultury, Lublin 2002, s. 10.

7 A. Tyszka, Kultura jest kultem wartości. Aksjologia społeczna. Studia i szkice, Wydawnictwo Antyk Marcin Dybowski, Komorów 1999, s. 51.

${ }^{8}$ O. Simonova, Emotional Culture as Sociological Concept. On Emotional Turn in Understanding of Modern Society, „Culture e Studi del Sociale-CuSSoc” 2019, t. 4, nr 2, s. 152.

9 J. Serrano-Puche, Emotions and Digital Technologies. Mapping the Field of Research in Media Studies, „MEDIA@LSE Working Paper Series” 2015, nr 33, s. 4, http://dadun.unav.edu/bitstream/10171/39702/1/WP33_FINAL-Emotions\%20and\%20Digital\%20Technologies.pdf (dostęp: 1.03.2021).

${ }_{10}$ M. Lünenborg, T. Maier, The Turn to Affect and Emotion in Media Studies, „Media and Communication" 2018, t. 6, nr 3, s. 1.

11 S.Y. Tettegah, Emotions, Technology, and Social Media, Elsevier Academic Press, London 2016.

12 Por. D. McQuail, Teorie komunikowania masowego, red. T. Goban-Klas, tłum. M. Bucholc, A. Szulżycka, Wydawnictwo Naukowe PWN, Warszawa 2007; M. Filiciak, Kultura konwergencji i luka uczestnictwa - w stronę edukacji medialnej, w: Kultura 2.0. Wyzwania cyfrowej przyszłości, red. E. Bendyk, M. Filiciak, J. Hofmokl i in., Polskie Wydawnictwo Audiowizualne, Warszawa 2007, ss. 43-52; L. Manovich, Język nowych mediów, tłum. P. Cypriański, Oficyna Wydawnicza Łośgraf, Warszawa 2012. 
który otrzymują ${ }^{13}$, a także wyboru emocji i kultury emocjonalnej, których za pośrednictwem mediów pragną doświadczać i kultywowaćl ${ }^{14}$ Uważa się, że narracja może wręcz stymulować odbiorców do konkretnego działania czy wpływać na codzienne życie, nawet gdy kontakt z mediami został zakończony ${ }^{15}$. Media, poprzez to, co i w jaki sposób ramują, sugerują odbiorcom ważność komunikatu i wywołują pożądane reakcje odbiorcze, podtrzymują tradycyjne wartości i postawy lub proponują nowe, uzasadniając jednocześnie ich sens. Biorąc pod uwagę zwiększającą się popularność nowych mediów, ciekawa będzie obserwacja tego, jakie emocje i towarzyszące im wartości i postawy będą promowane, zwłaszcza że mają one wpływ także na selekcję i unikanie informacji przez odbiorców ${ }^{16}$ oraz na stosunek odbiorców do konkretnych kwestii i wybory behawioralne $e^{17}$. Ma to szczególne znaczenie w okresach kryzysów, takich jak epidemie i pandemie, kiedy istotne jest, aby media pomogły odbiorcy w definiowaniu własnej wspólnoty, budowaniu wspólnego języka, w tym także języka emocji, i przekazywały wiedzę zakorzenioną w realności ${ }^{18}$. Media masowe poprzez sposób, w jaki prezentują wiadomości, są przede wszystkim dostarczycielami ram interpretacyjnych odbieranych treści medialnych ${ }^{19}$ i znacząco wpływają na postrzeganie i ocenę przedstawianych atrybutów i kwestii. Dlatego też w centrum zainteresowania autora będą emocje i towarzyszące im wartości oraz postawy jako przedmiot ramy interpretacyjnej, nie zaś jako mediator decydujący o jej końcowym efekcie, czyli reakcji odbiorców ${ }^{20}$.

13 J.N. Cappella, H.S. Kim, D. Albarracín, Selection and Transmission Processes for Information in the Emerging Media Environment. Psychological Motives and Message Characteristics, „Media Psychology" 2015, t. 18, nr 3, s. 396-424.

14 T.M de los Santos, R.L. Nabi, Emotionally Charged. Exploring the Role of Emotion in Online News Information Seeking and Processing, „Journal of Broadcasting \& Electronic Media” 2019, t. 63, nr 1, ss. 39-58.

${ }^{15}$ K. Oatley, Why Fiction May be Twice as True as Fact. Fiction as Cognitive and Emotional Stimulation, „Review of General Psychology” 1999, t. 3, nr 2, s. 101-117; R.A. Mar, K. Oatley, The Function of Fiction is the Abstraction and Simulation of Social Experience, „Perspectives on Psychological Science" 2008, t. 3, nr 3, s. 173-192; H.M. Chang, L. Ivonin, M. Rauterberg, Unconscious Emotions in Media Content, w: Handbook of Digital Games and Entertainment Technologies, red. R. Nakatsu, M. Rauterberg, P. Ciancarini, Springer, Singapore 2017, s. 1323-1351.

16 T.M de los Santos, R.L. Nabi, Emotionally Charged..., s. 43.

17 K. Döveling, A.A. Harju, D. Sommer, From Mediatized Emotion to Digital Affect Cultures. New Technologies and Global Flows of Emotion, „Social Media + Society”, styczeń 2018, s. 1-11.

18 B. Kovach, T. Rosenstiel, The Elements of Journalism. What Newspeople Should Know and The Public Should Expect, Three Rivers Press, New York 2014, s. 12.

19 Por. W. Gamson, A. Modigliani, The Changing Culture of Affirmative Action, w: Research in Political Sociology, red. R. Braungart, Jai Press, London 1987, s. 137-177; A.R.T. Schuck, A. Feinholdt, News Framing Effects and Emotions. Research Trends and Developments, w: Emerging Trends in the Social and Behavioral Science, red. R. Scott, S. Kosslyn, John Wiley and Sons, Hoboken 2015.

20 S. Lecheler, A.R.T. Schuck, C.H. de Vreese, Dealing with Feelings. Positive and Negative Discrete Emotions as Mediators of News Framing Effects, „Communications - The European Journal of Communication Research" 2013, t. 38, nr 2, s. 189-209. 
Badania emocji w mediach mają swoje korzenie w klasycznych pracach Arliego Hochschilda, Thomasa Scheffa, Theodora Kempera, Jana Stetsa i Jonathana Turnera ${ }^{21}$. Stają się one jednym z najważniejszych aspektów komunikowania medialnego ${ }^{22}$. Chociaż potrafimy intuicyjnie określić i nazwać emocje, które przeżywamy, to z perspektywy teoretycznej i analitycznej trudno o ich systematyczną klasyfikację i spójną definicję. „Język emocji jest tak zróżnicowany, że chociaż istnieją setki różnych słów używanych do opisania emocji, to samo słowo emocji może nadal mieć różne znaczenie w różnych kulturach, nawet tych używających tego samego języka" ${ }^{23}$. Uwspólniając jednak różne podejścia badawcze i teoretyczne, można uznać, że istnieją cztery najbardziej uniwersalne (powtarzające się w większości podejść teoretycznych), podobnie definiowane i rozpoznawane we wszystkich kulturach emocje: strach, smutek, złość i szczęście ${ }^{24} \mathrm{i}$ to one będą stanowiły podstawę do analizy wartości i postaw w emocjonalnych narracjach medialnych.

Głównym celem artykułu jest znalezienie odpowiedzi na pytania: w jaki sposób media obrazują wartości i postawy w przekazach nasyconych emocjami

21 A.R. Hochschild, The Managed Heart. Commercialization of Human Feeling, University of California Press, Berkeley 2003 [1983]; A.R. Hochschild, The Commercialization of Intimate Life. Notes from Home and Work, University of California Press, Berkeley 2007; T. Scheff, Microsociology. Discourse, Emotion and social Structure, The University of Chicago Press, Chicago 1990; T. Scheff, Bloody Revenge. Emotions, Nationalism and War, Routledge, 1994; T. Scheff, Emotions, the Social Bond and Human Reality. Part/Whole Analysis, Cambridge University Press, Cambridge 1997; T. Scheff, S.M. Retzinger, Emotions and Violence. Shame and Rage in Destructive Conflicts, Lexington Books, Lexington 1991; T.D. Kemper, Themes and Variations in the Sociology of Emotions, w: Research Agendas in the Sociology of Emotions, red. T. D. Kemper, State University of New York Press, New York 1990, s. 3-23; T.D. Kemper, Predicting Emotions from Social Relations, „Social Psychology Quarterly” 1991, t. 54, nr 4, s. 330-342; T.D. Kemper, R. Collins, Dimensions of Microinteraction, „American Journal of Sociology" 1990, t. 96, nr 1, s. 32-68; J. Stets, J.H. Turner, Handbook of the Sociology of Emotions, t. 2, Springer, Dordrecht 2014.

22 H.M.Chang, L. Ivonin, M. Rauterberg, Unconscious Emotions in Media Content, w: Handbook of Digital Games and Entertainment Technologies..., s. 7.

23 J.R. Davitz, The language of emotion, Academic Press, London 1969.

24 Badacze emocji w różny sposób typologizują je i dzielą, wskazując te, które według nich są powszechne. I tak chociażby Paul Ekman definiuje sześć podstawowych emocji: radość, smutek, wstręt, strach, zaskoczenie i złość, T. Kemper: szczęście, strach, złość smutek, Jaak Panksepp: poszukiwanie, wściekłość, strach, pożądanie, troska, żal (dawniej panika) i zabawa, Klaus Scherer i Harald Wallbott: radość, strach, złość, smutek, wstręt, wstyd i poczucie winy, Philip Johnson-Laird i Keith Oatley: szczęście, smutek, złość, strach i odraza. Por. P. Ekman, An Argument for Basic Emotions, "Cognition and Emotion” 1992, t. 6, nr 3-4, s. 169-200; T.D. Kemper, Themes and Variations...; tenże, Predicting Emotions...; T.D. Kemper, R. Collins, Dimensions...; J. Panksepp, Chapter 8 Fear and Anxiety Mechanisms of the Brain. Clinical Implications, w: Principles of Medical Biology, t. 14, red. E.E. Bittar, N. Bittar, Elsevier, [b.m.] 2000, s. 155-177; K.R. Scherer, H.G. Wallbott, Evidence for Universality and Cultural Variation of Differential Emotion Response Patterning, "Journal of Personality and Social Psychology" 1994, t. 66, nr 2, s. 310-328; P.N. Johnson-Laird, K. Oatley, Basic Emotions, Rationality, and Folk Theory, „Cognition and Emotion” 1992, t. 6, nr 3-4, s. 201-223. 
w okresie pandemii COVID-19 i czy prezentowane wartości są uzależnione od rodzaju emocji, który dominuje w przekazie. Do analizy zebrano materiał wizualny w postaci zdjęć i rysunków w liczbie 515, opublikowanych na kontach instagramowych (wzięto pod uwagę feedy) ogólnonarodowych dzienników $\mathrm{z}$ różnych krajów.

Struktura artykułu jest następująca - w pierwszej części omówione są założenia metodologiczne (cele, hipotezy, charakterystyka metod i korpusu badawczego). Druga część poświęcona jest wynikom analiz. W ostatniej części znalazły się uwagi końcowe o charakterze podsumowującym.

\section{Założenia metodologiczne: cele i hipotezy badawcze}

Ogłoszenie globalnej pandemii (jak się później okazało, była to pierwsza fala epidemii wirusa) oraz związanych z nią obostrzeń i lockdownów w decydujący sposób wpłynęly na kontent medialny i to, jakie emocje oraz towarzyszące im wartości i postawy były promowane przez media. Dlatego też celem badawczym niniejszego tekstu będzie znalezienie odpowiedzi na pytania: 1) jakie wizualne narracje o wartościach i postawach konstruują i narzucają media mainstreamowe w różnych krajach na swoich kanałach instagramowych w czasie pandemii COVID-19 oraz 2) czy narracje o wartościach są uzależnione od emocji dominującej w przekazie.

W analizie zawartości i treści materiałów wizualnych (którą przyjęto jako metodę badawczą) ważny jest zasób skojarzeń dyktowanych nie przez indywidualne predylekcje odbiorcy, związane z jego unikalnymi doświadczeniami biograficznymi, ale przez reguły kulturowe, będące dziedzictwem historycznej tradycji zbiorowości ${ }^{25}$, dlatego założono, że w obliczu pandemii narracje emocjonalne o wartościach będą zróżnicowane narodowo. A zatem pierwsza hipoteza badawcza brzmi następująco:

H1: w narracjach emocjonalnych mediów narodowych będą pojawiały się różne zestawy wartości.

Nie bez powodu przyjęto optykę narodową. Uważa się, że „kultura jest zintegrowaną całością wartości, zachowań i ich wytworów, wykształcanych i przyswajanych w grupie, służących międzyosobowej komunikacji i tylko w tej grupie w pełni zrozumiałych"26. Zatem przekazy medialne, będące wytworem

25 P. Sztompka, Socjologia wizualna. Fotografia jako metoda badawcza, Wydawnictwo Naukowe PWN, Warszawa 2005, s. 82.

${ }^{26}$ L. Dyczewski, Kultura polska..., s. 37. Por. także tenże, Trwałość kultury polskiej, w: Wartości w kulturze polskiej, red. L. Dyczewski, Fundacja Pomocy Szkołom Polskim na Wschodzie im. T. Goniewicza, Lublin 1993, s. 32. 
konkretnej kultury, powinny być nasycone jej elementami i charakterystycznym dla niej centrum kulturowym.

Drugim ważnym w kontekście pandemii spostrzeżeniem dotyczącym wartości jest to, że w społeczeństwie nie wszystkie one są jednakowo ważne, stanowią układ hierarchiczny, poza tym jednostki w odmienny sposób w różnych okresach cenią poszczególne wartości, co oznacza, że te same wartości mogą być inaczej rozumiane i realizowane w życiu publicznym i prywatnym. „Konfiguracje wartości są zmienne, choć same wartości są wieczne"27. Można zatem założyć, że okres pandemii, który bardzo mocno doświadczył ludzi na całym świecie, był czasem strat, cierpienia, bólu, izolacji, zawieszenia relacji społecznych, ale i konieczności funkcjonowania w nowych, trudnych warunkach, wpłynął na przekaz medialny, w którym nadawcy afirmowali z jednej strony wartości witalne, a także towarzyszące im postawy konformistyczne, strachu oraz obawy o zdrowie i życie, $\mathrm{z}$ drugiej zaś wartości duchowe i postawy prospołeczne ukierunkowane na innych. A zatem kolejne hipotezy badawcze będą brzmiały następująco:

H2: w analizowanym materiale częściej niż inne będą pojawiały się wartości witalne i duchowe oraz

H3: w analizowanym materiale częściej niż inne będą pojawiały się postawy konformistyczne i prospołeczne.

Drugie pytanie badawcze skupia się na tym, jaki zestaw wartości towarzyszy określonym emocjom. Każda $\mathrm{z}$ analizowanych emocji wyraża się na czterech poziomach: odczucia cielesne, ekspresywne gesty, sytuacja społeczna i kultura emocjonalna ${ }^{28}$, założono więc, że społeczny czy też kulturowy kontent (do którego zaliczyć można wartości i postawy ${ }^{29}$ ) każdej emocji będzie się różnił. Takie założenie bazuje także na stwierdzeniu, że nie można z całą pewnością uznać, iż wszystkie emocje są społecznie konstruowane, dostępnych jest bowiem wiele badań i danych potwierdzających uniwersalność niektórych emocji i ich ekspresji niezależnie od kultury ${ }^{30}$. Jaime Jiménez mówi o wspólnocie biologicznej, która sposób przeżywania określonej emocji, a co za tym idzie, towarzyszące jej wartości i postawy czyni uniwersalnymi dla wszystkich ludzi ${ }^{31}$. Ostatnia hipoteza zatem brzmi:

27 A. Tyszka, Kultura jest kultem..., s. 175.

28 Por. S.L. Gordon, Social Structural Effects on Emotions, w: Research Agendas in the Sociology of Emotions..., s. 145-179; tenże, The Sociology of Sentiments and Emotions, w: Social Psychology. Sociological Perspectives, red. M. Rosenberg, R. Turner, Basic Book, New York 1981, s. 562-592.

29 Por. R.A. Thamm, The Classification of Emotions, w: Handbook of the Sociology of Emotions. Handbooks of Sociology and Social Research, red. J.E. Stets, J.H. Turner, Springer, Boston 2006, s. 11-37.

30 T.D. Kemper, Predicting Emotions...

31 J. Jiménez, Semiology for Artists and Designers, Zona Limite, [b.m.] 2018. 
H4: każda emocja na poziomie kultury emocjonalnej będzie charakteryzowała się innym zestawem wartości i postaw, który będzie determinował funkcje poszczególnych narracji. I tak zakłada się, że narracje nasycone radością będą pełniły funkcję pocieszania, dlatego będą dominowały w nich wartości duchowe i hedonistyczne oraz postawy prospołeczne i ukierunkowane na bliźniego, zaś trzy pozostałe emocje będą pełniły funkcję podporządkowywania i w związku z tym będą dominowały wartości witalne wzmocnione postawami konformistycznymi i prospołecznymi.

\section{Metody badawcze i organizacja badań}

Uznano, że najlepszą metodą, która pozwoli znaleźć odpowiedzi na pytania badawcze i zweryfikuje słuszność postawionych hipotez, będzie ilościowa i jakościowa analiza zawartości. Podstawowa idea interpretacji semiologicznej zakłada, że obraz fotograficzny jest znakiem lub układem znaków, za którymi kryją się znaczenia kulturowe ${ }^{32}$, a w tym wypadku szczególnie interesująca będzie narracja aksjologiczna, którą można odczytać z obrazu. Analiza tej narracji musi zatem przyjąć schemat interpretacyjny bazujący na ramie ikonicznej, czyli konotacyjnej $j^{33}$. Badanie przeprowadzono w oparciu o klucz kategoryzacyjny zbudowany dla każdej z analizowanych emocji nieco inaczej (zawartość klucza determinowana była atrybutami konkretnej emocji), natomiast podsiadający identyczny schemat. Jednostką analizy było zdjęcie/rysunek. W pierwszej kolejności oceniono, czy pojawia się na nim przynajmniej jedna z emocji (i tak wśród 515 wylosowanych materiałów wizualnych radość wystąpiła 136 razy, strach 55 razy, smutek 46 razy, zaś złość 14 razy. Łącznie materiałów wizualnych, w których zaobserwowano narrację emocjonalną, było 251), przy czym występowanie emocji musiało mieć charakter ewidentny, niebudzący wątpliwości. Emocja musiała być obecna już w warstwie denotacyjnej. Następnie obrazy te analizowano na czterech poziomach przyjętych jako szkielet ramy medialnej. Pierwszy z nich to odczucia cielesne, czyli typowe dla konkretnej emocji objawy somatyczne jak uśmiech, łzy, otwarte usta. Drugi poziom to ekspresywne gesty, np. przytulenie, trzymanie za rękę, pokazywanie znaku zwycięstwa, zaciskanie pięści. Dwa pozostałe to sytuacja społeczna i kultura emocjonalna, czyli rytuały, wytwory kulturowe, symbole, wartości i postawy. Do analizy zebrano materiał wizualny w postaci zdjęć i rysunków związanych z tematyką pandemii COVID-19 opublikowanych na kontach instagramowych trzech ogólnonarodowych dzienników z najwyższym nakładem na dzień 9 października 2020 (o ile miały

32 P. Sztompka, Socjologia wizualna..., s. 81.

33 R. Barthes, Image. Music. Text, Fontana Press, London 1977, s. 36-37. 
aktywny profil na Instagramie) z Brazylii, Chin, Hiszpanii, Polski, Szwecji, Włoch, USA i Wielkiej Brytanii ${ }^{34}$. Okres badawczy obejmuje 23 tygodnie od 24 lutego do 2 sierpnia, a zatem pierwszą falę SARS-CoV-2. Z każdego dziennika wylosowano po 23 wpisy instagramowe (najczęściej po jednym z każdego tygodnia). W przypadku dzienników chińskich, ze względu na brak kont instagramowych, do próby badawczej włączono wszystkie fotografie opublikowane na kontach instagramowych dwóch chińskich anglojęzycznych dzienników („China Daily News” i „People’s Daily”). W przypadku dwóch innych dzienników: szwedzkiej „Göteborgs Posten” i polskiej „Rzeczpospolitej” wzięto bez losowania wszystkie materiały, które dotyczyły koronawirusa, opublikowane w badanym okresie, gdyż było ich zbyt mało, żeby przeprowadzić losowanie. Pełną listę mediów poddanych analizie wraz ze szczegółową liczebnością analizowanych materiałów i występujących emocji przedstawiono w Załączniku 1 na końcu artykułu. Wpis potraktowano jako dotyczący pandemii COVID-19, jeśli opatrzony był hasztagiem związanym z pandemią (\#coronawirus, \#covid, \#SARS-CoV-2, \#lockdown, \#pandemia, \#kwarantanna) - sytuacje takie były jednak rzadkie. Dużo częściej w opisach materiałów wizualnych szukano słów kluczowych związanych z pandemią: covid, coronavirus, pandemia, epidemia, lockdown, kwarantanna itp.

\section{Prezentacja wyników badań}

Na wstępie należy zaznaczyć, że prezentowane poniżej dane, ze względu na niereprezentatywną próbę, nie mogą być poddane wnioskowaniu statystycznemu ani uogólniane na całość przekazów. Stanowią natomiast ważny kontekst i wprowadzenie dla analizy jakościowej prowadzonej w dalszej części tekstu. Pozwalają także zweryfikować hipotezy oraz zaobserwować pewne tendencje, które warto po uzupełnieniu próby badawczej przetestować statystycznie.

W materiale poddanym analizie zawartości i treści udało się wyodrębnić grupy pojawiających się na obrazach wartości i postaw. I tak, zgodnie z typologią wartości Maxa Schelera ${ }^{35}$, pogrupowano zaobserwowane w materiale badawczym wartości na (w nawiasie podano liczbę wszystkich obserwacji łącznie dla wszystkich emocji):

- religijne (2): Bóg;

- witalne (114): życie, zdrowie, utrzymanie dobrej kondycji;

34 Dobór krajów był celowy. Zadecydowano, że do analizy zostaną wybrane państwa, które w tamtym czasie najmocniej doświadczyły skutków epidemii, tj.: Włochy, Hiszpania, Brazylia, USA, oraz których rządy prezentowały różne podejście do stanu epidemii: Szwecja, Wielka Brytania. Do próby włączono także Chiny, z których epidemia rozszerzyła się na cały świat, i Polskę.

35 Zob. J. Cutting, Max Scheler's Theory of the Hierarchy of Values and Emotions and its Relevance to Current Psychopathology, „History of Psychiatry” 2016, t. 27, nr 2, s. 220-228. 
- duchowe (264): miłość, przyjaźń, rodzina, wolność, prawda, sprawiedliwość, samostanowienie, wspólnota, bezpieczeństwo, tradycja, możliwość samostanowienia;

- utylitarne (16): praca, pieniądze, pożywienie, polityka;

- hedonistyczne (31): zabawa, przyjemność, hobby, beztroskie dzieciństwo. Wyniki całościowej analizy zawartości pozwalają na pozytywną weryfikację hipotezy H2. Tak jak zakładano, narracja emocjonalna w mediach skupiała się na wspieraniu i podtrzymywaniu dwóch kategorii wartości: witalnych, co miałoby skłaniać odbiorców do przyjmowania postaw konformistycznych, oraz duchowych, zachęcających do przyjęcia postaw prospołecznych. Potwierdzają to wyniki analizy całościowej zaobserwowanych postaw i częstotliwość ich występowania, które pozwalają na pozytywną weryfikację hipotezy H3. Rozkład poszczególnych grup postaw prezentuje się następująco:

- postawy prospołeczne (301): okazywanie szacunku innym, pomaganie innym, wdzięczność, skracanie dystansu społecznego, okazywanie miłości i przywiązania, szacunek wobec zmarłych, podtrzymywanie tradycji;

- postawy konformistyczne (103): dostosowywanie się do obostrzeń, strach przed śmiercią/chorobą;

- postawy ukierunkowane na siebie (38): utrzymanie formy, angażowanie się w hobby, beztroska, pracowitość, przedsiębiorczość, zapobiegliwość;

- postawy konfrontacyjne (34): sprzeciw wobec władzy, odwaga, niedostosowywanie się do obostrzeń.

W celu weryfikacji hipotezy H4 przeprowadzono analizę częstości występowania poszczególnych wartości i postaw w podziale na emocje. Następnie wybrano pięć najczęściej pojawiających się jako dominujące w narracji emocjonalnej.

Tabela 1. Wartości i postawy w narracjach nasyconych emocją radości

\begin{tabular}{|l|c|c|c|}
\hline \multicolumn{1}{|c|}{ Postawy } & $\begin{array}{c}\text { Liczebność } \\
\mathrm{N}=136\end{array}$ & Wartości & $\begin{array}{c}\text { Liczebność } \\
\mathrm{N}=136\end{array}$ \\
\hline Szacunek wobec innych, troska o innych & 83 & Miłość & 52 \\
\hline Okazywanie sobie miłości i czułości & 52 & Rodzina & 51 \\
\hline Dostosowywanie się do obostrzeń & 45 & Zabawa & 25 \\
\hline Niesienie pomocy & 35 & Przyjaźń & 14 \\
\hline Odwaga & 21 & Wolność & 12 \\
\hline
\end{tabular}

Źródło: opracowanie własne.

Emocji radości w narracjach medialnych towarzyszył zbiór wartości, w którym dominowały wartości duchowe, uzupełnione wartością hedonistyczną. Są one realizowane poprzez dominujące postawy prospołeczne, podporządkowujące i uzupełnione jedną postawą z grupy postaw konfrontacyjnych (odwaga). 
Taka narracja ma charakter pozytywny, afirmujący, ma odwrócić uwagę od zagrożenia zdrowia i życia, niepewności przyszłości, kryzysu ekonomicznego i szkód społecznych spowodowanych przez lockdown. Nadawcy wrócili do komunikowania fundamentalnych wartości, jakimi są: miłość, rodzina, zabawa (która pojawiła się jako sposób na odreagowanie izolacji), przyjaźń i wolność. Częstotliwość występowania poszczególnych wartości może odzwierciedlać priorytety przeciętnego obywatela, który w obliczu wielopłaszczyznowego kryzysu zwraca się ku temu, co w jego życiu najważniejsze, i często przewartościowuje swoje życie i zmienia priorytety, odkładając na bok pracę, dbanie o wygląd czy nawet pieniądze i dobrobyt.

Tabela 2. Wartości i postawy w narracjach nasyconych emocją smutku

\begin{tabular}{|l|c|c|c|}
\hline \multicolumn{1}{|c|}{ Postawy } & $\begin{array}{c}\text { Liczebność } \\
\mathrm{N}=46\end{array}$ & Wartości & $\begin{array}{c}\text { Liczebność } \\
\mathrm{N}=46\end{array}$ \\
\hline Szacunek wobec zmarłych & 35 & Życie & 32 \\
\hline Okazywanie sobie miłości, uczuć & 12 & Rodzina & 25 \\
\hline Dostosowywanie się do obostrzeń & 12 & Miłość & 20 \\
\hline Szacunek dla innych & 12 & Zdrowie & 11 \\
\hline Przedsiębiorczość & 1 & Przyjaźń & 3 \\
\hline
\end{tabular}

Źródło: opracowanie własne.

Emocji smutku w narracjach medialnych towarzyszył zbiór wartości łączący w sobie wartości witalne i duchowe w bardzo podobnych proporcjach. Postawy je uzewnętrzniające należą do grupy postaw prospołecznych, ukierunkowanych na samego siebie i konformistycznych, przy czym stosunkowo wysoka częstotliwość występowania tych drugich łącznie z postawą szacunku wobec zmarłych ma wzmacniać poczucie konieczności podporządkowywania się reżimom sanitarnym i łagodzić postawy konfrontacyjne. Jednocześnie poprzez zwrot ku wartościom fundamentalnym taka narracja ma pełnić funkcję oswajającą ze śmiercią i stratą oraz podtrzymywać świadomość kruchości życia i zdrowia, a także potrzeby dbania o nie.

Tabela 3. Wartości i postawy w narracjach nasyconych emocją strachu

\begin{tabular}{|l|c|c|c|}
\hline \multicolumn{1}{|c|}{ Postawy } & $\begin{array}{c}\text { Liczebność } \\
\mathrm{N}=55\end{array}$ & Wartości & $\begin{array}{c}\text { Liczebność } \\
\mathrm{N}=55\end{array}$ \\
\hline Strach przed śmiercią, chorobą & 39 & Zdrowie & 38 \\
\hline Szacunek dla innych & 20 & Życie & 29 \\
\hline Szacunek dla zmarłych & 13 & Bezpieczeństwo & 28 \\
\hline Zapobiegliwość & 8 & Rodzina & 8 \\
\hline Dostosowywanie się do obostrzeń & 7 & Miłość & 3 \\
\hline
\end{tabular}

Źródło: opracowanie własne. 
Emocja strachu w narracjach medialnych pojawia się ze zbiorem wartości, do którego weszły wartości witalne i duchowe, przy czym te pierwsze stanowią większość obserwacji. Wzmocnione są one przez postawy konformistyczne, prospołeczne, w tym szacunek wobec zmarłych oraz ukierunkowane na siebie. Częstotliwość prezentowania poszczególnych wartości i postaw sugeruje, podobnie zresztą jak w przypadku tekstów nasyconych radością, że strach zmusza ludzi do zwracania się ku oraz doceniania spraw najważniejszych, chociaż wydawałoby się oczywistych, takich jak zdrowie, życie, bezpieczeństwo, szacunek dla ludzi, od których zależy ludzkie życie i zdrowie. Ten zbiór wartości oraz postaw, podobnie jak w przypadku narracji z dominującą emocją smutku, ma wzmacniać zachowania konformistyczne, podporządkowywanie się reżimom sanitarnym, a także wywołać poczucie zagrożenia, które podtrzymywałoby te postawy.

Tabela 4. Wartości i postawy w narracjach nasyconych emocją złości

\begin{tabular}{|l|c|l|c|}
\hline \multicolumn{1}{|c|}{ Postawy } & $\begin{array}{c}\text { Liczebność } \\
\mathrm{N}=14\end{array}$ & \multicolumn{1}{|c|}{ Wartości } & $\begin{array}{c}\text { Liczebność } \\
\mathrm{N}=14\end{array}$ \\
\hline Sprzeciw wobec władzy & 10 & Bezpieczeństwo & 10 \\
\hline Szacunek wobec zmarłych & 4 & Prawda & 6 \\
\hline & & Sprawiedliwość & 4 \\
\hline & & Wolność & 4 \\
\hline & & Możliwość samostanowienia & 2 \\
\hline
\end{tabular}

Źródło: opracowanie własne.

Emocja złości pojawiła się w nielicznych materiałach. Towarzyszyły jej dwie postawy: konfrontacyjna, pojawiająca się w większości obserwacji, i prospołeczna, będąca uzewnętrznieniem wartości duchowych. Zawartość tych zbiorów mogłaby sugerować, że narracja zachęca odbiorców do podejmowania działań antyreżimowych i antysystemowych. Jednakże bardziej prawdopodobne jest, biorąc pod uwagę zwłaszcza wartości, że narracje te pełnią funkcję wentyla bezpieczeństwa, który ma pacyfikować postawy konfrontacyjne.

Powyższa analiza pozwala zatem na pozytywną weryfikację hipotezy $\mathrm{H} 4$, bo jak się okazuje, zbiory wartości i postaw w narracjach odmiennych emocji są różne i przekazy te pełnią inne funkcje.

Aby zweryfikować hipotezę H1, mówiącą o zróżnicowaniu narracji narodowych pod kątem występujących w nich wartości, dokonano analizy częstotliwości ich pojawiania się w mediach narodowych konkretnych państw (badaniu poddano narracje medialne z ośmiu państw) i wybrano pięć najczęściej ukazywanych wartości. Poniżej zaprezentowano ich katalog (w nawiasie liczba narracji narodowych, w których pojawia się dana wartość):

- zdrowie (8); 
- rodzina (7);

- miłość (7);

- bezpieczeństwo (6);

- życie (5);

- zabawa (5);

- wspólnota (1);

- tradycja (1).

Okazuje się, że wbrew oczekiwaniom narracje emocjonalne mediów narodowych zawierają bardzo podobne zestawy wartości. Jest to zaskakujące, biorąc pod uwagę ogromne zróżnicowanie kulturowe państw, z których pochodzą przekazy medialne poddane analizie. Być może jednak okoliczność pandemii COVID-19 uwspólniła doświadczenia zarówno pozytywne, jak i negatywne ludzi na całym świecie, zaś przekazy medialne dostosowując się do pewnej uniwersalnej sytuacji, oparły swoje narracje o podstawowe konfiguracje ${ }^{36}$. Drugim wyjaśnieniem może być fakt, że media w dobie pandemii pełnią niebagatelną w społeczeństwie rolę ramującą, polegającą na wyjaśnianiu, tłumaczeniu, narzucaniu pożądanych przez decydentów postaw i afirmującą wartości mogące je wzmacniać. Należy zatem uznać, że hipoteza H1 została zweryfikowana negatywnie.

\section{Wnioski i dyskusja}

Na podstawie wyników przeprowadzonej analizy, pomimo ich niereprezentatywnego charakteru, można postawić tezę, że w obliczu jakiegoś zagrożenia (w tym przypadku pandemii COVID-19) media przyjmują różne strategie, najczęściej pocieszają (pomniejszanie negatywnych skutków i „oswajanie” pandemii) lub straszą (wzmocnienie kontroli społecznej w celu kształtowania postaw konformistycznych wobec reżimów sanitarnych członków społeczeństw dotkniętych pandemią). W ramach tych strategii odwołują się do konkretnych zbiorów wartości i postaw, które mają wzmacniać siłę narracji emocjonalnej oraz wywoływać pożądany skutek wśród odbiorców. Na bazie tych narracji tworzy się emocjonalna wspólnota, która jest kształtowana przez medialny kontent, i jak pokazują analizy, uwspólniona globalnie (chociaż wniosek ten nie jest podparty analizą statystyczną pozwalającą na uogólnienie analiz na wszystkie przekazy medialne). Podobne wnioski sformułowała Barbara Rosenwine, która obserwuje tworzenie się w różnych okresach innych „emocjonalnych wspólnot”, podobnych wspólnotom społecznym ${ }^{37}$. Z pewnością można uznać, że mamy

36 Zob. Jiménez, Semiology...

37 B.H. Rosenwein, Emotional Communities in the Early Middle Ages, Cornell University Press, Ithaca 2006, s. 24-25. 
do czynienia z utworzeniem się wspólnoty ludzi czasów pandemii, którzy doświadczają naprzemiennie strachu i poczucia zagrożenia oraz pocieszenia.

\section{Ograniczenia}

Materiał nie jest reprezentatywny, dlatego nie jest łatwo uogólnić wyniki analiz na cały przekaz medialny poszczególnych mediów, a zaproponowane funkcje narracji nie mogą być uznane za uniwersalne dla emocjonalnych przekazów medialnych. Biorąc jednak pod uwagę propozycję J. Jiménez, że typowe konfiguracje wywołują te same emocje, a te z kolei są nierozłączne z zestawem określonych wartości i postaw, podobnych wniosków można by oczekiwać od analizy zdjęć dotyczących pandemii COVID-19 w różnych mediach w innych krajach świata. Dalsze badania tego obszaru z pewnością pomogłyby odpowiedzieć na to pytanie.

Załącznik 1. Źródła poddane analizie wraz z liczebnością materiałów pochodzących z każdego z nich i rozkładem poszczególnych emocji

\begin{tabular}{|c|c|c|c|c|c|c|c|}
\hline Państwo & Źródło & $\begin{array}{c}\text { Liczba } \\
\text { materiałów } \\
\text { poddanych } \\
\text { analizie } \\
\end{array}$ & Radość & Strach & Smutek & Złość & Razem (\%) \\
\hline \multirow{3}{*}{ Polska } & Rzeczpospolita & 23 & 1 & 2 & 1 & 0 & \multirow{3}{*}{$13(18,8)$} \\
\hline & Gazeta Wyborcza & 23 & 5 & 0 & 1 & 1 & \\
\hline & Fakt & 23 & 2 & 0 & 0 & 0 & \\
\hline \multirow{3}{*}{ Brazylia } & Estadão & 23 & 5 & 5 & 2 & 2 & \multirow{3}{*}{$53(76,8)$} \\
\hline & Folha de S. Paulo & 23 & 3 & 11 & 6 & 1 & \\
\hline & O Globo & 23 & 6 & 6 & 4 & 2 & \\
\hline \multirow{3}{*}{ Hiszpania } & ABC Diario & 23 & 7 & 2 & 3 & 1 & \multirow{3}{*}{$38(55)$} \\
\hline & El Mundo & 23 & 7 & 5 & 2 & 0 & \\
\hline & El País & 23 & 6 & 2 & 2 & 1 & \\
\hline \multirow{3}{*}{ Włochy } & Il Sole 24 Ore & 23 & 2 & 0 & 0 & 0 & \multirow{3}{*}{$29(42)$} \\
\hline & la Repubblica & 23 & 12 & 0 & 4 & 0 & \\
\hline & Corriere della Sera & 23 & 9 & 0 & 1 & 1 & \\
\hline \multirow{3}{*}{ Szwecja } & Svenska Dagbladet & 23 & 9 & 1 & 0 & 0 & \multirow{3}{*}{$24(44,4)$} \\
\hline & Göteborgs-Posten & 8 & 0 & 0 & 1 & 0 & \\
\hline & Dagens Nyheter & 23 & 8 & 1 & 2 & 2 & \\
\hline \multirow{2}{*}{ Chiny } & China Daily News & 32 & 5 & 2 & 2 & 0 & \multirow{2}{*}{$17(36,2)$} \\
\hline & People's Daily & 15 & 7 & 1 & 0 & 0 & \\
\hline \multirow{3}{*}{$\begin{array}{l}\text { Wielka } \\
\text { Brytania }\end{array}$} & The Times & 23 & 11 & 1 & 2 & 0 & \multirow{3}{*}{$41(59,4)$} \\
\hline & The Daily Mail & 23 & 15 & 0 & 3 & 0 & \\
\hline & Daily Mirror & 23 & 2 & 6 & 1 & 0 & \\
\hline
\end{tabular}




\begin{tabular}{|c|c|c|c|c|c|c|c|}
\hline Państwo & Źródło & $\begin{array}{c}\text { Liczba } \\
\text { materiałów } \\
\text { poddanych } \\
\text { analizie }\end{array}$ & Radość & Strach & Smutek & Złość & Razem (\%) \\
\hline \multirow{3}{*}{ USA } & $\begin{array}{l}\text { The New York } \\
\text { Times }\end{array}$ & 23 & 5 & 5 & 4 & 0 & \multirow{3}{*}{$36(52,1)$} \\
\hline & $\begin{array}{l}\text { The Wall Street } \\
\text { Journal }\end{array}$ & 23 & 1 & 4 & 4 & 2 & \\
\hline & USA Today & 23 & 8 & 1 & 1 & 1 & \\
\hline Razem & & 515 & $\begin{array}{c}136 \\
(26,4 \%)\end{array}$ & $\begin{array}{c}55 \\
(106 \%)\end{array}$ & $\begin{array}{c}46 \\
(8,9 \%)\end{array}$ & $\begin{array}{c}14 \\
(2,7 \%)\end{array}$ & $\begin{array}{c}251 \\
(48,7 \%)\end{array}$ \\
\hline
\end{tabular}

\section{Bibliografia}

Barthes R., Image. Music. Text, Fontana Press, London 1977.

Cappella J.N., Kim H.S., Albarracín D., Selection and Transmission Processes for Information in the Emerging Media Environment. Psychological Motives and Message Characteristics, "Media Psychology" 2015, t. 18, nr 3, s. 396-424, DOI: 10.1080/15213269.2014.941112.

Chang H.M., Ivonin L., Rauterberg M., Unconscious Emotions in Media Content, w: Handbook of Digital Games and Entertainment Technologies, red. R. Nakatsu, M. Rauterberg, P. Ciancarini, Springer, Singapore 2017, s. 1323-1351, DOI: 10.1007/978-981-4560-50-4_41.

Cutting J., Max Scheler's Theory of the Hierarchy of Values and Emotions and Its Relevance to Current Psychopathology ,"History of Psychiatry" 2016, t. 27, nr 2, s. 220-228, DOI: 10.1177/0957154x16631693.

Davitz J.R., The language of emotion, Academic Press, London 1969.

de los Santos T.M, Nabi R.L., Emotionally Charged. Exploring the Role of Emotion in Online News Information Seeking and Processing, , Journal of Broadcasting \& Electronic Media" 2019, t. 63, nr 1, s. 39-58, DOI: 10.1080/08838151.2019.1566861.

Döveling K., Harju A.A., Sommer D., From Mediatized Emotion to Digital Affect Cultures. New Technologies and Global Flows of Emotion, "Social Media + Society", styczeń 2018, s. 1-11, DOI: 10.1177/2056305117743141.

Dyczewski L., Kultura polska w procesie przemian, TN KUL, Lublin 1995.

Dyczewski L., Trwałość i zmienność kultury polskiej, Akademia Społeczna, Wojewódzki Dom Kultury, Lublin 2002.

Dyczewski L., Trwałość kultury polskiej, w: Wartości w kulturze polskiej, red. L. Dyczewski, Fundacja Pomocy Szkołom Polskim na Wschodzie im. T. Goniewicza, Lublin 1993, s. 11-50.

Ekman P., An Argument for Basic Emotions, "Cognition and Emotion” 1992, t. 6, nr 3-4, s. 169-200, DOI:10.1080/02699939208411068.

Filiciak M., Kultura konwergencji i luka uczestnictwa - w stronę edukacji medialnej, w: Kultura 2.0. Wyzwania cyfrowej przyszłości, red. E. Bendyk, M. Filiciak, J. Hofmokl i in., Polskie Wydawnictwo Audiowizualne, Warszawa 2007, s. 43-52.

Gamson W., Modigliani A., The Changing Culture of Affirmative Action, w: Research in Political Sociology, red. R. Braungart, Jai Press, London 1987, s. 137-177.

Geertz C., Interpretacja kultur. Wybrane eseje, tłum. M. Piechaczek, Wydawnictwo UJ, Kraków 2005.

Gordon S.L., Social Structural Effects on Emotions, w: Research Agendas in the Sociology of Emotions, red. T.D. Kemper, State University of New York Press, New York 1990, s. 145-179.

Gordon S.L., The Sociology of Sentiments and Emotions, w: Social Psychology. Sociological Perspectives, red. M. Rosenberg, R. Turner, Basic Book, New York 1981, s. 562-592. 
Harrison L., Dlaczego kultury nie sposób przecenić?, w: Kultura ma znaczenie. Jak wartości wpływaja na rozwój społeczeństw, red. L.E. Harrison, S.P. Huntington, tłum. S. Dymczyk, Zysk i S-ka, Poznań 2003, s. 17-41.

Hochschild A.R., The Commercialization of Intimate Life. Notes From Home and Work, University of California Press, Berkeley 2007.

Hochschild A.R., The Managed Heart. Commercialization of Human Feeling, University of California Press, Berkeley 2003.

Jiménez J., Semiology for Artists and Designers, Zona Limite, [b.m.] 2018.

Johnson-Laird P.N., Oatley K., Basic Emotions, Rationality, and Folk Theory "I"Cognition and Emotion" 1992, t. 6, nr 3-4, s. 201-223, DOI: 10.1080/02699939208411069.

Kemper T.D., Collins R., Dimensions of Microinteraction, „American Journal of Sociology” 1990, t. 96, nr 1, s. 32-68, http://www.jstor.org/stable/2780692.

Kemper T.D., Themes and Variations in the Sociology of Emotions, w: Research Agendas in the Sociology of Emotions, red. T.D. Kemper, State University of New York Press, New York 1990, s. 3-23.

Kemper T.D., Predicting Emotions from Social Relations, „Social Psychology Quarterly” 1991, t. 54, nr 4, s. 330-342, DOI: 10.2307/2786845.

Kłoskowska A., Kultura, w: Encyklopedia kultury polskiej XX wieku. Pojęcia i problemy wiedzy o kulturze, red. A. Kłoskowska, Wiedza o Kulturze, Wrocław 1991, s. 17-50.

Kovach B., Rosenstiel T., The Elements of Journalism. What Newspeople Should Know and The Public Should Expect, Three Rivers Press, New York 2014.

Lecheler S., Schuck A.R.T., de Vreese C.H., Dealing with Feelings. Positive and Negative Discrete Emotions as Mediators of News Framing Effects, "Communications - The European Journal of Communication Research" 2013, t. 38, nr 2, s. 189-209, DOI: 10.1515/commun-2013-0011.

Lünenborg M., Maier T., The Turn to Affect and Emotion in Media Studies, „Media and Communication" 2018, t. 6, nr 3, s. 1, DOI: 10.17645/mac.v6i3.1732.

Manovich L., Język nowych mediów, tłum. P. Cypriański, Oficyna Wydawnicza Łośgraf, Warszawa 2012.

McQuail D., Teorie komunikowania masowego, red. T. Goban-Klas, tłum. M. Bucholc, A. Szulżycka, Wydawnictwo Naukowe PWN, Warszawa 2007.

Mar R.A., Oatley K., The Function of Fiction is the Abstraction and Simulation of Social Experience, "Perspectives on Psychological Science” 2008, t. 3, nr 3, s. 173-192, DOI: 10.1111/j.1745$-6924.2008 .00073 . x$.

Nowak S., Pojęcie postawy w teoriach i stosowanych badaniach społecznych, w: Teorie postaw, red. S. Nowak, PWN, Warszawa 1973, s. 17-69.

Oatley K., Why Fiction May Be Twice as True as Fact. Fiction as Cognitive and Emotional Stimulation, „Review of General Psychology" 1999, t. 3, nr 2 s. 101-117, DOI: 10.1037/1089-2680.3.2.101.

Panksepp J., Chapter 8 Fear and Anxiety Mechanisms of the Brain. Clinical Implications, w: Principles of Medical Biology, t. 14, red. E.E. Bittar, N. Bittar, Elsevier, [b.m.] 2000, s. 155-177, DOI: 10.1016/ S1569-2582(00)80010-0.

Rosenwein B.H., Emotional Communities in The Early Middle Ages, Cornell University Press, Ithaca 2006.

Scheff T., Bloody Revenge. Emotions, Nationalism and War, Routledge, 2019.

Scheff T., Emotions, The Social Bond and Human Reality. Part/Whole Analysis, Cambridge University Press, Cambridge 1997.

Scheff T., Microsociology. Discourse, Emotion and Social Structure, The University of Chicago Press, Chicago 1990.

Scheff T., Retzinger S.M., Emotions and Violence. Shame and Rage in Destructive Conflicts, Lexington Books, Lexington 1991.

Scherer K.R., Wallbott H.G., Evidence for Universality and Cultural Variation of Differential Emotion Response Patterning, , Journal of Personality and Social Psychology"1994, t. 66, nr 2, s. 310-328, DOI: 10.1037/0022-3514.66.2.310. 
Schuck A.R.T., Feinholdt A., News Framing Effects and Emotions. Research Trends and Developments, w: Emerging Trends in The Social and Behavioral Science, red. R. Scott, S. Kosslyn, John Wiley and Sons, Hoboken 2015, ss. 1-15, DOI: 10.1002/9781118900772.etrds0241.

Serrano-Puche J., Emotions and Digital Technologies. Mapping the Field of Research in Media Studies, „MEDIA@LSE Working Paper Series"2015, nr 33, http://dadun.unav.edu/bitstream/10171/39702/1/ WP33_FINAL-Emotions\%20and\%20Digital\%20Technologies.pdf (dostęp: 1.03.2021).

Simonova O., Emotional culture as sociological concept: on emotional turn in understanding of modern society, "Culture e Studi del Sociale-CuSSoc" 2019, t. 4, nr 2, s. 147-160.

Stets J., Turner J. H., Handbook of the Sociology of Emotions, t. 2, Springer, Dordrecht 2014.

Sztompka P., Socjologia wizualna. Fotografia jako metoda badawcza, Wydawnictwo Naukowe PWN, Warszawa 2005.

Tettegah S.Y., Emotions, Technology, and Social Media, Elsevier Academic Press, London 2016.

Thamm R.A., The Classification of Emotions, w: Handbook of the Sociology of Emotions. Handbooks of Sociology and Social Research, red. J.E. Stets, J.H. Turner, Springer, Boston 2006, s. 11-37, DOI: 10.1007/978-0-387-30715-2_2.

Tyszka A., Kultura jest kultem wartości. Aksjologia społeczna. Studia i szkice, Wydawnictwo Antyk Marcin Dybowski, Komorów 1999.

\section{Streszczenie}

Celem artykułu było znalezienie odpowiedzi na dwa pytania badawcze: 1) jakie wizualne narracje o wartościach i postawach konstruują i narzucają media mainstreamowe w różnych krajach na swoich kanałach instagramowych w czasie pandemii COVID-19 oraz 2) czy narracje o wartościach są uzależnione od emocji dominującej w przekazie. W celu weryfikacji postawionych w tekście hipotez zastosowano analizę zawartości i treści 515 materiałów wizualnych opublikowanych na kanałach instagramowych przez ogólnonarodowe dzienniki z różnych krajów. Wyniki przeprowadzonych analiz pozwoliły na sformułowanie następujących wniosków: 1) postawy i wartości prezentowane w przekazach medialnych o tematyce pandemicznej są zdeterminowane aktualną sytuacją epidemiologiczną i pełnią funkcje oswajania i pocieszania oraz straszenia, 2) zbiory wartości i postaw są zróżnicowane w narracjach nasyconych konkretną emocją, 3) zbiór wartości pojawiający się w narracjach różnych mediów narodowych pochodzących z różnych krajów świata jest uniwersalny.

Słowa kluczowe: wartości, postawy, emocje, narracje emocjonalne, analiza zawartości i treści, Instagram

\section{Values and attitudes in emotional media narratives. Content analysis of mainstream media messages during the first wave of SARS-CoV-2}

\section{Summary}

The aim of this article is to address the two following research questions: 1 . What visual narratives about values and attitudes are constructed and imposed by mainstream media in different countries on their Instagram channels during the COVID pandemic; and 2. Whether narratives about values are dependent on the emotions encoded in the message. In order to verify the hypotheses, the authors analyse the content of 515 visual messages published on Instagram by dailies representing different countries. The research results allowed for the following conclusions: 1 . The attitudes and values presented in media messages concerning the pandemic are determined by the current epidemiological situation 
and they are evoked to make the recipients feel more familiarized with the pandemic situation, get comforted but sometimes also scared or warned; 2 . The set of values and attitudes differ depending on the particular emotion that prevails in a particular narrative; 3 . The set of values appearing in the narratives of various national media globally is universal in nature.

Key words: values, attitudes, emotions, emotional narratives, content and content analysis, Instagram 
